Solange G. Coutinho [UFPR]

\title{
Design da Informação para Educação
}

\author{
Information Design for Education
}

\begin{abstract}
Educação, Design da Informação, Pesquisa
Este artigo apresenta a relação intrínseca entre Design da Informação e Educação utilizando como objeto de estudo os artefatos gráficos. O propósito é apresentar algumas inquietações acerca da concepção de Arte e do universo imagético na escola, e do estado dos artefatos educacionais adotados para este fim no Brasil. Este trabalho, de certa forma, se propõe a uma reflexão do passado que permite compreender, no presente, a natureza da relação conflitante entre conteúdo e forma de tais artefatos. Apresenta experiências de pesquisas em Design da Informação do Departamento de Design da Universidade Federal de Pernambuco voltadas à prática educacional, discutindo a responsabilidade do Designer da Informação neste campo.
\end{abstract}

\section{Education, Information Design, Research}

This paper presents the intrinsic relationship between Information Design and Education through the study of graphic artefacts. The aim is to present some disquieting aspects concerning the concepts of Art at school, the use of image and, the state of educational artefacts within Brazilian schools. This work also suggests a reflection on the past in order to understand the nature of the conflicting relation between the form and contents of such artefacts. Investigations are also presented concerning information design research for early education conducted at the Design Department of the Federal University of Pernambuco, bringing to surface a discussion upon the responsibility of the Information Designer in such a matter.

\section{Inquietações acerca do Design da Informação para Educação}

As inquietações aqui levantadas estão relacionadas com os aspectos que interligam o Design da Informação e a Educação, especialmente na mediação entre as duas áreas - o estudo da linguagem gráfica. Investigações que abordem estudos neste campo de sombreamento (no sentido positivo) poderão beneficiar, de maneira significativa, a qualidade do ensino através da visão sistemática, organizacional e prospectiva própria da atividade do Design da Informação. Atribuições estas que possibilitam diagnosticar e identificar problemas, avaliar e analisar situações de uso, e propor a otimização dos sistemas informacionais (instrucionais, comunicacionais, hierárquicos, estruturais, entre outros) dos artefatos educacionais.

Entretanto, esta inter-relação é ainda tímida, se levarmos em conta a produção científica na área, tomando como exemplo os Congressos Internacionais de Design da Informação - Recife (2003), e São Paulo (2005). A presença da área temática da Educação nos dois eventos demonstra a visão crítica de seus organizadores vislumbrando a importância da mesma para o país. Todavia, ao se fazer um apanhado das comunicações nestes eventos, verifica-se que esta área é ainda acanhada quando comparada às demais. Aproximadamente 15\% das comunicações referem-se ao papel do design da informação na educação e, em sua maioria, trata-se de questões relativas às novas tecnologias. Compreende-se, assim, a sua importância, visto que as mesmas vêm modificando o mundo e as relações humanas, impondo um novo modo de pensar, alterando as regras dos jogos científicos e culturais. No entanto, poucas são as comunicações relacionadas com o uso e/ou eficácia dos artefatos gráficos analógicos (livros didáticos, murais, fichas - exercícios de aula, cartazes, entre outros) presentes até hoje em volume ainda significativo no ambiente educacional.

Noutra perspectiva, as investigações em relação ao processo ensino-aprendizagem; estágios da representação gráfica infantil; conteúdo do livro didático; modelos pedagógicos; universo imagético infanto-juvenil; e, entre outros, o desenho como tema têm sido estudados por 


\section{Infodesıgn}

são educadores, historiadores da arte e, principalmente, psicólogos por mais de um século e sãouniverso imagético infanto-juvenil; e, entre outros, o desenho como tema têm sido estudados por educadores, historiadores da arte e, principalmente, psicólogos por mais de um século e são preciosas fontes de informação. Todavia, o estudo da eficácia dos sistemas informacionais presentes neste universo é pouco representativo.

Nossas inquietações não estão apenas relacionadas com o papel fundamental do design da informação para educação naquilo que o compete em sua preocupação central, a eficáciaeficiência dos sistemas informacionais, mas acima de tudo na relação direta da produção imagética e verbal explorada nas escolas. Esta produção implica três problemáticas: a) na formação de professores de arte e suas estratégias como originadores e consumidores de informação; b) nas soluções propostas pelos alunos como originadores e consumidores de informação; e, c) na produção e seleção dos artefatos educacionais por adultos (especialistas ou não) nesse mesmo contexto.

Para compreender os problemas postos, organizamos este artigo em quatro partes: 1 ) Breves considerações acerca do ensino da arte no Brasil; 2) O dilema do universo imagético na escola; 3) A produção e utilização de artefatos gráficos na escola; 4) Experiências de pesquisas em Design da Informação voltados à prática educacional.

\section{Breves considerações acerca do ensino da arte no Brasil}

Entendendo que os avanços tecnológicos são centrais hoje no Brasil no âmbito da educação e da cultura, principalmente quando falamos de educação à distância, inclusão digital, e conseqüentemente inclusão cultural, a exemplo dos projetos do Ministério da Cultura, Cultura Viva (que envolve kits multimídia e de áudio-visual para as comunidades governamentais e nãogovernamentais); o ambiente colaborativo de aprendizagem e-Prolnfo (sítio de educação à distância) do Ministério da Educação proposto pela SEED - Secretaria de Educação à Distância e, outras ações nesta direção, não é de se estranhar que os professores estejam valorizando com entusiasmo a adoção desses instrumentos e que os pesquisadores situem suas investigações nessa esfera.

Barbosa (2001) aponta que a valorização do "novo" é também conseqüência da falta de conhecimento do passado, e que este desconhecimento acarreta uma ausência crítica da introdução de novos objetivos educacionais, muitas vezes calcados em métodos e experiências formulados por períodos culturais anteriores e, complementa:

\footnotetext{
' Os professores de arte, escravizados pelo "novo", estão aceitando métodos conservadores mistificados por máscaras modernas, devido à falta de conhecimento sobre o passado e à ignorância teórica. (Barbosa, 2001, p:35).
}

A experiência histórica mostra que, num país economicamente e politicamente dependente, o sistema educacional é um reflexo dessa dependência. Originalmente, a dependência internalizava apenas uma relação econômica que, em seguida, converteu-se numa posição que caracteriza todas as relações sociais (Barbosa, 2001). O sistema educacional é dependente como conseqüência da dependência geral da sociedade a que serve. Através da educação, os valores e aspirações, já alcançados pelas sociedades independentes, são transmitidos às sociedades dependentes, impedindo com isso a formação de seus próprios valores. Assim nos tornamos incapazes de modelar a nossa cultura e, conseqüentemente, o nosso modelo educacional, porque não somos livres para determinar nosso próprio sistema de valores, prossegue Barbosa.

A educação brasileira sendo formada por uma colagem de experiências vindas de fora, é pouco provável que o professor de arte tenha consciência dessa realidade. Promovem, por vezes, mudanças em seus métodos, porém essas mudanças nunca são estruturais, pois nunca se dão conta que grande parte do sistema educacional brasileiro encontra-se calcado em soluções vindas da França, dos Estados Unidos ou da Inglaterra, que implicam o mesmo grau de renúncia da consciência social. Barbosa é contundente quando coloca que:

' Se uma sociedade dependente, tal como a sociedade brasileira, não pode ter um modelo educacional peculiar ao Brasil, estamos diante da tarefa de lutar, pelo menos, por nossa sobrevivência cultural. (Barbosa, 2001, p.40).'

Barbosa (Op.cit.) aponta também que para compreender a arte/educação no Brasil é necessário compreender a sua história: o seu período inicial, como o desenvolvimento artístico implementado pelos jesuítas vindos de Portugal no século XVI, passando pela influência francesa que norteou as Escolas de Belas Artes e o grande impacto britânico do século XIX na educação secundária. A ingerência advinda das escolas de missionários americanos do início do século XX foi definitiva e relevante na formação da legislação educacional brasileira. 
No período seguinte que compreende de 1914 a 1927, recebemos a influência da pedagogia experimental quando despontam as primeiras pesquisas sobre as características da expressão visual através do desenho - visto apenas como instrumento de investigação de seus processos mentais, portanto não foi considerado como atividade importante em si mesma. Entre

1927 e 1935, o Movimento da Escola Nova estimulou as reformas educacionais com o objetivo de democratização da sociedade; com isso despertaram-se preocupações em adaptar modelos estrangeiros às condições nacionais. A educação artística sofreu as repercussões da Semana de Arte Moderna, com atividades encabeçadas por Mário de Andrade e Anita Malfatti e, definitivamente, as idéias de John Dewey são incorporadas ao modelo educacional brasileiro nesse período (Barbosa, 2001).

Entre 1935 a 1948, período da ditadura Vargas, o grupo da Escola Nova foi afastado do Ministério da Educação e a arte/educação brasileira padeceu sensivelmente nos currículos das escolas elementares e secundárias, promovendo a valorização de estereótipos fortemente estimulada nas salas de aula. No período seguinte (1945-1958), fase de redemocratização do país, alguns princípios do Movimento da Escola Nova foram restabelecidos, todavia a educação foi dominada por interesses políticos e não por uma preocupação científica, acredita Barbosa (Op.cit.). Houve uma supervalorização da arte como livre-expressão e uma aceitação da mesma como atividade extracurricular e, até extra-escolar - fase da criação das Escolinhas de Arte no Brasil, influência de Viktor Löwenfeld e Sir Herbert Read. Neste período também se localiza a expansão da 'educação de massa' com a criação do SENAC pela Federação Nacional do Comércio e, SENAI e SESI pela Confederação Nacional da Indústria (CNI) (Barbosa, 2001).

Ainda de acordo com Barbosa (Ibid., p:43), entre 1958 e 1963 foi sancionada por lei federal a organização de classes experimentais, o que permitiu o desenvolvimento de uma atitude voltada para a experimentação em arte nas escolas comuns. Observam-se ainda fortes influências das concepções de Paulo Freire sobre educação. Esse período foi decisivo para a emancipação da arte/educação, visto que as tendências culturais aliadas à abertura política e social do país, promoveram mudanças significativas na educação, liderados pela política de expansão econômica e modernização das instituições públicas de Juscelino Kubitschek. A geração de emprego e a expansão da capacidade de consumo da população levaram a uma atmosfera de euforia, todavia a "incapacidade" do Estado não conseguiu evitar a desigualdade e as distorções sociais, gerando uma mobilização de estudantes, a união dos trabalhadores e ligas camponesas, intensificando, segundo Barbosa (Op.cit.) a auto-identificação da cultura e da educação brasileira, fazendo aflorar no país movimentos de valorização da cultura popular.

Em 1961 é decretada a Lei de Diretrizes e Bases da Educação Nacional, reivindicada desde o início do período da República, permitindo a flexibilidade necessária à experimentação, promovendo algumas experiências significativas em arte/educação nas escolas públicas e particulares. A Universidade de Brasília, imbuída de uma concepção humanista, foi também instalada neste período. Intensos debates acerca do papel e da natureza da universidade se realizaram neste âmbito; rejeitavam-se a tecnocracia e a quantificação, promovendo-se discussões substanciais sobre educação, sendo isto, portanto, um marco para o sistema educacional brasileiro (Barbosa, 2001). Contudo, a partir de 1964, inúmeros professores são demitidos e outros renunciam diante das pressões do governo, encerrando o primeiro momento da Universidade de Brasília. Da mesma forma, o movimento de emancipação educacional influenciado pela proposta de Paulo Freire sofre ruptura como todos os outros setores da sociedade. Instala-se a partir desse momento um modelo tecnocrata predominado pela quantificação, e o Estado assume o papel de "administrador e fiscalizador" de escolas, argumenta Barbosa (Op.cit.).

Em 1973, o governo federal criou um curso universitário para preparar professores para a disciplina de educação artística, visto que na reforma educacional de 1971 foi determinado o ensino obrigatório de Arte no currículo do primeiro grau (7 a 14 anos). Estes cursos de graduação chamados de Licenciatura Curta em Educação Artística com duração de dois anos tinham a intenção de tornar os professores aptos a lecionar música, teatro, desenho, dança, artes plásticas e desenho geométrico. Segundo Barbosa (2001, p:48) a formação desse professor polivalente refletia a cópia incorreta de modelos estrangeiros, reduzindo o princípio da interdisciplinaridade, ou artes relacionadas, conhecido nas escolas americanas, para o conceito de polivalência adotado no Brasil.

Mesmo com a adoção do Curso de Licenciatura Plena em Educação Artística, onde o estudante, após cursar a Licenciatura Curta, em mais dois anos, pode se especializar em música, artes visuais ou artes cênicas, poucas escolas se interessam em contratar tais professores. Alguns Estados não exigem este diploma e, as escolas particulares não estão interessadas em aceitar tais professores, uma vez que se espera melhor remuneração dos mesmos. 


\section{Infodesıgn}

Entende-se que a primeira função da arte na escola é auxiliar os estudantes a se tornarem mais humanos, valorizando a arte como um aspecto fundamental de suas vidas, todavia esta prática está submetida a um desenvolvimento de uma autoridade cognitiva e social da escola. Barbosa é contundente quando observa que o compulsório ensino da arte nas escolas brasileiras faz desta um instrumento ideológico argumentando que:

' A arte serve à instituição escolar para mostrar abertura e ausência de preconceito contra as ciências humanas e contra a criação. Porém, através da quantificação sem qualificação foram eliminados os possíveis efeitos que a arte poderia exercer no despertar de um raciocínio crítico e independente. (Barbosa, 2001, p:52).'

Observamos nestas breves considerações apontadas por Ana Mae Barbosa que, muitas vezes, não compreendemos que estamos envoltos na dependência de modelos educacionais advindos de outras nações e conseqüentemente de outras culturas. Adotamos experiências exteriores sem crítica e sem interesse de aprofundarmo-nos na nossa própria trajetória, desrespeitando a nossa multiculturalidade. Desta forma estamos perdendo a valiosa oportunidade de transformar a arte no meio de humanizar a escola e de ajudar na formação de nossas múltiplas identidades culturais. Não é por acaso que estranhamos o universo imagético encontrado em nossas escolas, descontextualizado da vida social dos alunos, e do forte repertório visual externo aos muros escolares. Não é à-toa que nos deparamos com um repertório gráfico limitado e limitador, e que imerso neste ambiente 'formador' de cultura visual, tenhamos nos tornado adultos inaptos a originar informação gráfica. Este é o dilema ao qual nos propomos investigar, com o olhar crítico do design da informaç̧ão, de forma a contribuir para uma ampliação dos seus usos por especialistas ou não-especialistas, originadores e/ou consumidores de informação visual.

\section{O dilema do universo imagético na escola}

Apesar da existência de legislação, a realidade que encontramos no ambiente educacional é, no mínimo, desastrosa. As escolas funcionam muitas vezes em precárias instalações, e não dispõem de condições de abrigar um espaço adequado ao trabalho de arte. Organizada como mais uma disciplina dentro dos currículos tecnicistas e com uma pequena carga horária semanal, a arte continua ainda a ser encarada, no universo da escola, como um mero lazer, uma distração ante as demais atividades 'sérias'.

Freqüentemente delega-se também ao professor de arte a incumbência de 'decorar' a escola e, de liderar as atividades cívicas e festivas. Neste sentido, é totalmente inócua a disciplina, visto que toda a estrutura física, a burocrática e a ideológica estão organizadas na direção da imposição de valores e do cerceamento da criatividade (Porcher, 1982, p:15).

A educação artística divide com a educação física o privilégio de serem ambas rejeitadas, explicitamente ou não, ao se ingressar no território da escola. Na hierarquia das disciplinas a serem trabalhadas, as disciplinas ligadas às artes situam-se nos espaços menos favorecidos do currículo escolar. O aluno pode dedicar-se às atividades artísticas, dentro da escola, 'se tiver tempo', ou seja, se tiver terminado todas as outras 'tarefas importantes'.

Talvez, esta seja uma das razões de não existir um sistema de avaliação de arte, uma vez que a educação artística é concebida como uma atividade e, não como uma disciplina, como muitos interpretam a LDB - Lei de Diretrizes e Bases de Educação Nacional (Lei no. 9.394/96). Em casos como este, são adotadas avaliações baseadas no bom comportamento, interesse e dedicação ao trabalho. As conseqüências são críticas: professores que nunca acessaram livros de arte; manuais de técnicas de desenho; ou qualquer outro insumo educacional dedicado ao fazer e pensar artístico. Como resultado, alunos desestimulados, frustrados e despreparados para o uso da linguagem visual e para a geração de uma linguagem gráfica adequada.

O desenho para a criança é antes de tudo sociabilizante, podendo revelar sentimentos que ela ainda não consegue expressar verbalmente, ou registrar acontecimentos complexos de descrever. Da mesma forma que a criança aprende a falar, a criança desenha pelo prazer de desenhar, manifestando a necessidade de agir sobre o mundo, comunicando-se com ele. Deflagrando uma ação de conquistar e modificar espaços. O processo de desenho é marcado por várias atitudes que são tomadas em grupo, como por exemplo, a forma e/ou a estratégia para representar algo observado ou imaginado.

Muitos professores ainda se perguntam por que ensinar arte se as crianças continuam a desenhar da mesma forma? Não entendendo que, assim como a linguagem falada e escrita, o desenho também passa por um amadurecimento, que por ausência da sua prática, neste caso, tende a ser inferior aos outros dois. Como a disciplina Artes Visuais não possui um conteúdo rígido, específico, e por ser muito abrangente, inclusive sendo transversal no conteúdo das outras disciplinas, o professor tem dificuldade em sua implementação. As dúvidas mais comuns dizem respeito ao material a ser usado em sala de aula, aos períodos da história da arte, à maneira de 
avaliar o aprendizado. A concepção de ensino da disciplina que entende arte visual como linguagem, é geralmente rejeitada pelos educadores. O ensino artístico visa prover as crianças de se tornarem sensíveis à obra-de-arte, a elaborar o seu universo imagético, a formar seus

referentes culturais. Em outras palavras, trata de tornar cada aluno apto a receber (consumidor) e gerar informações visuais (originador). Desta forma o ensino artístico, em todos os níveis, merece atenção, mais do que qualquer outro setor da vida escolar.

O desenho constitui uma atividade vital onde a interdisciplinaridade acontece de modo exemplar. Cabe aos professores, em sua formação, dominar esta rica ferramenta. Através do desenho são estabelecidos os estágios de desenvolvimento. Adotaremos aqui, aqueles propostos por Moreira (1999, pp.32-46), a qual destaca o desenho como forma de jogo: a) Etapa da garatuja (sensório-motor : de 0 a 2 anos) é marcada pela conquista da coordenação motora, dos rabiscos 'incompreensíveis' para o adulto e do prazer do gesto; b) Etapa do símbolo (pré-operacional: 2 a 7 anos) é também conhecida como a etapa das formas fechadas, da conquista do círculo, e de representações que começam a se estruturar como linguagem, quando passam a representar flores, girinos, etc.; c) Etapa da regra (operacional concreta: 7 a 11 anos) é a etapa da preocupação em representar o observado, interesse pelas formas e proporção à busca pelo realismo. A criança ganha uma consciência apurada das suas imperfeições, das cópias que realiza. Neste ponto, por volta dos oito ou nove anos o problema do 'não sei desenhar' é revelado e as crianças entram numa fase de insatisfação e de abandono do desenho. Dificilmente as crianças superam esta etapa sem a ajuda do professor (Buoro, 2003). Como argumenta Edwards (1984, pp:213-214) "elas querem aprender a ver e merecem toda a ajuda que precisam". E o professor está preparado para ajudá-las? Essa é outra inquietação nossa.

O olhar do professor sobre o desenho é determinado pelas suas concepções adquiridas durante sua vida acadêmica e profissional. Esse conhecimento modela sua postura na escola e a forma como ele observa o desenho das crianças, sendo permeado pelo incentivo ou advertência, ou mesmo pela indiferença. O padrão esperado pelos professores em relação aos alunos, e a si mesmo, é o da semelhança com o real (na visão adulta), indicado por alguns manuais.

Essa postura desconsidera as inúmeras percepções de um mesmo objeto, pela mesma pessoa em momentos diferentes, ou por outras. Percepções estas que estão ligadas à experiência que o indivíduo tem do objeto. A busca pela 'perfeição' do desenho traz o conceito de 'feio' e 'bonito' sem considerar as possibilidades expressivas e/ou comunicacionais do desenho. $\mathrm{O}$ ato de rabiscar é visto como não saber desenhar, pois se espera que o desenho seja associado a algo real. O rabisco, por ser orientado pela mão e visão, retrata uma percepção visual, originando formas e recursos que enriquecem a representação gráfica.

É natural que professores tenham essa postura e que não consigam perceber a visualidade do desenho, pois Ihes falta vivência dessa linguagem. Os educadores, de forma geral, estão mais envolvidos com o pragmatismo do cotidiano, com ações imediatas e a estética da mídia. Eles têm pouco contato com outras formas gráficas e visuais.

De acordo com resultados do estudo de Formiga (2003), o comportamento dos professores é, às vezes, pejorativo, utilizando conceitos pessoais para julgar o desenho, não motivando o aluno. Geralmente as crianças e jovens desenham sem nenhuma intervenção dos 'mestres', tampouco revelam o caminho para resultados satisfatórios. Pode-se também verificar o repertório repetitivo dos desenhos sobre um mesmo tema. Desta forma, torna-se urgente a utilização de métodos pedagógicos específicos e progressivos - "os únicos capazes de produzirem a alfabetização estética, sem a qual toda expressão permanece impotente e toda criação é ilusória" (Porcher, 1982, p:27).

A afirmação acima nos parece pertinente, visto que a nova LDB (Lei no. 9.394/96) contribuiria para uma alfabetização estética, pois estabelece no seu artigo 26 , §2 ${ }^{\circ}$ que: "O ensino da arte constituirá componente curricular obrigatório, nos diversos níveis da educação básica, de forma a promover o desenvolvimento cultural dos alunos". Compreende-se, portanto, que o ensino da arte é obrigatório pela LDB no Ensino Fundamental e no Ensino Médio. Entretanto, muito pouco se tem feito para que a lei seja cumprida de modo satisfatório, a exemplo de algumas escolas "que incluem Arte em apenas uma das séries de cada um desses níveis porque a LDB não explicitou que esse ensino é obrigatório em todas as séries", comenta Barbosa (2002, p:13, grifo nosso). Da mesma forma, complementa Barbosa, que, utilizando o subterfúgio da interdisciplinaridade, algumas Secretarias de Educação incluem todas as Artes na disciplina de Literatura, como forma de eliminar as outras formas de Arte, fazendo prevalecer a hierarquia da supremacia da linguagem verbal e, em conseqüência, o desprezo pela linguagem visual.

O nosso problema se intensifica, pois é exatamente no período em que o ensino da Arte é negligenciado, que a criança mais precisa de instrumental e repertório para realizar suas representações gráficas. Portanto, é a própria escola que não está apta a ajudá-la quando mais 


\section{Infodesıgn}

necessita, assim contribuindo totalmente para o abandono da linguagem gráfica pictórica nessa fase da vida escolar e, conseqüentemente, em sua vida adulta.

\section{A produção e utilização de artefatos gráficos na escola}

A produção e utilização do material didático nas escolas, não só nas públicas estaduais ou municipais, mas também nas privadas, concentram seus esforços na utilização do que denominamos de mensagens visuais (cartazes, sinalizações, murais, entre outros, produzidos pelos professores e, em alguns casos pelos alunos); fichas de aula (em geral, fotocopiadas ou ainda mimeografadas, concebidas e executadas pelos professores); e o livro didático, estes impressos e produzidos fora do ambiente escolar por especialistas (incluindo os designers), todavia escolhidos pelos coordenadores e professores.

As mensagens visuais podem ser agrupadas de acordo com Coutinho \& Vanderlei (2003) em: a) aniversário; b) personagens de histórias infantis; c) datas sazonais (Páscoa, Dia das Mães, Dia do Índio, etc.); e) material didático (utilizados para auxiliar na transmissão de informações educacionais); f) lista de presença (utilizadas para a freqüência do aluno na escola); d) mensagens educativas e/ou informativas (noções de educação doméstica e ambiental, por exemplo). As fichas de aula por sua vez são utilizadas diariamente como suporte às atividades pedagógicas desenvolvidas em diversas disciplinas ou matérias. Geralmente em formato ofício, monocromática e de baixa resolução em sua reprodução.

\section{O livro didático: um artefato gráfico atemporal}

Observamos a introdução, por vezes, de livros didáticos atraentes e de design gráfico inovador, utilizando-se de novas figuras de linguagem na apresentação, contudo adotando métodos de ensino que remontam ao século XIX. Barbosa (2001, p:35) exemplifica este fato com um livro de educação artística para a sexta série, onde é proposto um exercício de ampliação de figuras com o intuito de desenvolver a percepção. O livro possui um design moderno e um convite coloquial ao trabalho: "Vamos brincar de máquina fotográfica". Ela aponta que os professores aceitam como novos estes exercícios, todavia desconhecem que tal método de ensino de desenho foi introduzido no Brasil no século XIX, sob o nome de "rede estimográfica" - baseado na concepção da percepção visual como uma função mecânica - concepção, segundo a autora, que experiências científicas realizadas no século XX demonstraram ser falsa.

Em seu desenvolvimento e processo de apreensão do conhecimento, a criança aprende através do que ela observa e sente em meio ao contexto no qual está inserida. No ambiente escolar, os livros de leitura, especialmente os livros didáticos, tornam-se um ponto de apoio essencial no processo de aprendizagem. Sabe-se da prática e da teoria relacionada, que os livros ilustrados despertam um interesse maior nas crianças para a percepção e apreensão do seu conteúdo. Assim, entende-se que há intrinsecamente um compromisso com a representação utilização da imagem - por todos os envolvidos no processo de elaboração do livro. Uma preocupação com o conteúdo e sua conseqüente forma, coerentes com o repertório da criança, promovendo assim uma relação de identidade com a sua realidade gerando um possível interesse maior. Mas será que isto ocorre de fato?

No estudo da Língua Portuguesa, por exemplo, é através das ilustrações que as crianças começam a 'aprender' as primeiras palavras. Dondis (1997) considera que expandir a capacidade de ver significa expandir a capacidade de entender uma mensagem visual, e, o que é ainda mais importante, de criar uma mensagem visual, pois a 'experiência visual' é uma extensão da capacidade que temos de criar e interpretar mensagens.

Estudos demonstram que a familiaridade do leitor com a informação gráfica é um aspecto fundamental na compreensão da mensagem, principalmente quando direcionada para um público com pouca ou nenhuma experiência com a comunicação pictórica (Goldsmith, 1984). Portanto, deve-se estar atento ao contexto em que a informação visual está inserida para não torná-la ambígua, demonstrando assim, a atenção devida ao repertório do artefato visual e antes de tudo, a importância de incentivar a leitura pictórica. Uma imagem pode se tornar ambígua ou complexa se isolada do seu contexto (por exemplo, uma fivela, representada isoladamente sem o cinto). Da mesma forma, imagens com elevado grau de elementos gráficos 'não essenciais', no sentido informacional, podem também se configurar de forma pansêmica, ou seja, passível de várias interpretações, independendo da resposta prevista pelo autor. Uma vez que a leitura de uma imagem pode ser afetada pela 'forma' em que a mensagem é visualmente representada, os seus aspectos gráficos de configuração devem ser trabalhados de forma a otimizar a sua compreensão (Freire, 2005).

A utilização da linguagem visual para a educação, principalmente a pictórica, necessita de certo rigor e parâmetros pré-determinados. Os atuais recursos visuais de comunicação que vêm 
sendo utilizados com fins pedagógicos são apresentados com critérios, no mínimo insuficientes para a validação e compreensão dos efeitos que produzem. Uma maior experiência visual significa uma compreensão mais fácil dos significados assumidos pelas suas formas.

Durante um longo período, o esforço na produção do livro se restringiu ao texto escrito e

ao seu conteúdo, as imagens desempenhavam um papel secundário ou decorativo. Hoje, porém, percebe-se uma mudança, a imagem começa a assumir um papel menos decorativo e mais 'ilustrativo', no sentido de apoiar e complementar o conteúdo textual. Este aspecto, no entanto, não é totalmente adotado nas escolas e tampouco em todos os livros didáticos. A relação imagética e textual precisa ser trabalhada de forma a contribuir objetivamente para o desenvolvimento da capacidade de observação e leitura visual das crianças.

O processo de aprendizagem da leitura e da escrita implica na correta associação da palavra na sua forma visual ou motora a um significado, portanto é fundamental que haja uma associação das palavras ao contexto dos exercícios e suas respectivas ilustrações.

A cada dia, de maneira mais intensa, podemos observar uma busca em diversificar os 'modelos' didáticos nos livros infantis. Os usos sociais da língua escrita, a diversidade dos modos de ler e a diversidade dos suportes de textos são exemplos de tais experiências nas escolas. $O$ livro didático é auxiliado pela adoção, em paralelo, de todo um conjunto de artefatos comunicacionais que outrora não era evidenciado no ambiente escolar: jornais, revistas, quadrinhos, rótulos, quadros e tabelas, placas, cartazes e peças publicitárias, principalmente nas escolas privadas.

Apesar do acréscimo de materiais sócio-educativos no ambiente escolar, o livro didático infantil, embora tenha sua importância reconhecida no processo de aprendizagem, é visto apenas como um instrumento de trabalho do professor, mesmo que muitas vezes este seja o 'único' instrumento disponível. Os processos de elaboração e aplicação destes livros necessitam ainda de uma revisão e critérios mais rigorosos. De acordo com o MEC:

' O livro didático constitui-se um instrumento de fundamental importância no processo científico de produção/aquisição/transmissão do conhecimento. É necessário, portanto, que seja claro, coerente e correto quanto aos conteúdos, e metodologicamente adequado ao fim a que se destina. (Guia do Programa Nacional do Livro Didático, MEC - 2005).'

Ao longo dos anos e das sucessivas avaliações, os números comprovam que a qualidade dos livros vem melhorando, porém alguns aspectos são negligenciados e devem ser cuidadosamente analisados - estes se referem particularmente à relação do conteúdo imagético dos livros didáticos infantis. Há indícios de que, não só as próprias editoras vêm sendo mais criteriosas na seleção dos livros que publicam, como também autores têm reformulado seus livros ou propõem novos livros atentos aos critérios de qualidade. Entretanto, em relação à avaliação das imagens utilizadas nos livros didáticos, a sua abordagem é muito genérica como descrito pelo MEC:

' As ilustrações devem estar bem distribuídas nas páginas e devem enriquecer as atividades textuais propostas. As ilustrações também devem evitar os estereótipos, os preconceitos e a propaganda. (Guia do Programa Nacional do Livro Didático, MEC - 2005).'

A análise dos aspectos gráficos das imagens é descartada na aprovação e recomendação dos livros didáticos, assim como não há referências ao conteúdo semântico destas imagens, não fazendo parte, portanto, do critério de seleção dos mesmos. Muitas vezes o autor apresenta a imagem de um objeto para que a criança o nomeie, mas como resposta ao exercício, solicita na verdade o 'conceito' dessa imagem. Outras vezes é também ignorada a experiência da criança consumidora da informação, pois alguns autores utilizam imagens que não fazem parte do repertório referente a sua faixa etária ou cultura na qual está inserida. Em um dos livros analisados por Freire (2005) foram encontrados, por exemplo, um exercício de vocabulário onde é representada a ilustração de um 'sanduíche' e o autor do livro solicita a palavra 'lanche' como resposta, ou seja, um conceito relacionado à imagem de um sanduíche. Em outro exercício de vocabulário são estudadas palavras com ' $x$ ', sendo apresentada à imagem de um menino se olhando no espelho e, a ilustração enfatizando o 'espelho'. Todavia, o autor solicita como resposta a palavra 'reflexo', a criança pode até saber que espelho não se escreve com ' $x$ ', mas acaba sendo induzida a escrever 'expelho', pois ela está 'vendo' um espelho em destaque na imagem. Aspectos como estes analisados por Coutinho \& Freire (2006) apontam o comprometimento sobremaneira da eficácia do processo ensino-aprendizagem.

Diante deste quadro, organizamos um Grupo de Estudo no Curso de Design da UFPE, cujo enfoque de investigação científica aborda o uso da Linguagem Gráfica no Ambiente Educacional como atividade acadêmica e inserida na estrutura curricular. Algumas pesquisas 


\section{Infodesıgn}

relatadas a seguir derivam deste grupo e/ou foram aprofundadas pelos alunos em suas monografias de conclusão de curso, assim como alguns jovens pesquisadores continuaram seus estudos no mestrado.

\section{Experiências de pesquisas em Design da Informação voltados à Prática Educacional}

A pesquisa na área de Design voltada à educação é iniciada na Universidade Federal de Pernambuco (UFPE) em 1984, envolvendo docentes, discentes, e recém formados dos antigos cursos de Programação Visual e Projeto do Produto da UFPE. Este grupo, no período de seis anos consecutivos desenvolveu três projetos de pesquisa em Design para Educação com financiamento do CNPq, além de bolsas de iniciação científica (IC) e de aperfeiçoamento (AP) para onze jovens pesquisadores, sendo estas: 1) Legibilidade em livros infantis: uma análise tipográfica (1984 a 1986) - por Solange Coutinho (UFPE), colaboração de Lia Monica Rossi (UFPB), com a participação de cinco bolsistas de IC; 2) Materiais lúdico-didáticos para deficientes visuais (1987 a 1989) - por Luiz Vidal de Negreiros Gomes, Ivan Assumpção de Macedo e Solange Coutinho, com a participação de dois bolsistas de AP; 3) A ilustração no livro didático infantil: uma análise da decodificação da imagem (1988 a 1990) - por Solange Coutinho, com a participação de quatro bolsistas de IC.

Esta experiência pioneira da pesquisa em Design para Educação, num tempo onde, como bem coloca Coelho (2005, p:37), estava centrada no axioma "Design se faz fazendo", encontrou resistência e certa descontinuidade - que não foi motivada pela falta de interesse dos órgão de fomento - mas no mínimo, pela 'estranheza' gerada quando da apresentação dos seus resultados em encontros de design, como os extintos ENDIs (Encontros Nacionais de Desenhistas Industriais) e, outros Fóruns Nacionais. Em outras palavras, com a ausência dos cursos de pósgraduação e dos espaços científicos próprios à sua difusão, a pesquisa ficou restrita ao terceiro plano no Brasil da época (em primeiro lugar, a prática e em segundo, o ensino). Não é à-toa que, em 1992, é criado o Laboratório de Programação Visual da UFPE, que teve como proposta ações de Pesquisa, Ensino e Extensão com o intuito de aproximar a sociedade da academia, experiência esta que estimulou a criação do Departamento de Design, em 1997, e um extenso programa contínuo de capacitação docente.

Muito embora este quadro tenha se revertido e a pesquisa e a pós-graduação hoje tenham posição de destaque, as dimensões (ensino, pesquisa e extensão) não podem estar dissociadas. Entendendo o design como um processo completo através de um conjunto amplo de domínios necessários para qualquer resultado, cada domínio requer um conjunto de habilidades, conhecimentos e cuidados. A teoria é fundamental para entendermos o domínio do conhecimento em design. O campo do design pode ser visto como uma profissão, uma disciplina, uma área. A profissão envolve a prática do design, a disciplina envolve a investigação de domínios plurais do design, e a área envolve a profissão, a disciplina e a troca constante de campos de investigação. Portanto, ensino, pesquisa e extensão são indissociáveis na co-produção de conhecimentos no campo universitário, principalmente na área de design.

Em 2000, é criado no Departamento de Design da UFPE o primeiro Curso de PósGraduação lato sensu em Design da Informação do país. Atualmente, este Curso encontra-se na sua quinta versão. No ano seguinte, foi instituído o Grupo de Pesquisa em Design da Informação no CNPq, hoje ampliado e em pleno funcionamento, cuja relação de suas pesquisas encontra-se descrita adiante. Em 2002, funda-se em Recife a SBDI - Sociedade Brasileira de Design da Informação, fruto da reflexão de pesquisadores do país em resposta a uma necessidade apontada desde 1993. Com a fundação da SBDI, organiza-se em 2003, no Recife, o $1^{\circ}$ Congresso Internacional em Design da Informação e o $1^{\circ}$ Congresso Nacional de Iniciação Científica em Design da Informação - CONGIC, o que demonstra a coerência e preocupação em revelar a produção científica inicial de nossos jovens. Ainda nessa perspectiva é criada também em 2003, a linha de pesquisa em Design da Informação no Mestrado em Design da UFPE.

O Grupo de Pesquisa em Design da Informação - GP InfoDesign, conta hoje com três linhas de pesquisa dedicadas à educação: 1) Artefatos Educacionais; 2) Linguagem Gráfica; 3) Educação Ambiental, esta última criada em 2006. Listaremos, a seguir, as monografias de graduação, os projetos de iniciação científica, as dissertações de mestrado e pesquisas já concluídas e em andamento, oriundos das duas primeiras linhas de pesquisa do GP InfoDesign voltados à prática educacional, considerando apenas aqueles relacionados com os artefatos educacionais analógicos.

\section{Monografias produzidas na área - Bacharelado em Design, UFPE:}

- Helena Pontes Bezerra LIMA. (2006). O Pipoca x Pele Coviti: uma discussão da representação gráfica do dualismo herói $x$ vilão no imaginário infantil; 
- José Fábio Luna da SILVA. (2006). Projeto gráfico: coleção de livros didáticos para o ensino fundamental;

- Érika Simona Santos FERREIRA. (2006). Representações pictóricas em artefatos educativos e instrucionais da área de saúde: um estudo de caso;

- Mariana Pitanga de MACEDO. (2006). Design editorial para alfabetizar - análise gráfica de livros didáticos de Português;

- Verônica Emília Campos FREIRE. (2005). A função semântica de imagens em livro didático infantil de língua portuguesa;

- Gustavo Neves GUSMÃO. (2004). AlphaBetica: uma família tipográfica para leitores iniciantes;

- Karla Fernanda Pereira PIRES. (2004). Design com tipos em livros infantis;

- Manuela de Burgos Cabral da COSTA. (2003). Tipografia em livros infantis;

- Bárbara Gomes FORMIGA. (2003). Nem tudo que tem tecla é computador - um estudo sobre o processo de desenho das professoras primárias do Recife;

- André Gustavo Soares da FONSECA. (2003). Jogos educativos;

- Eva Rolim MIRANDA. (2003). Desenho de memória versus desenho com estimulação da imagem mental: um estudo;

- Renata Garcia WANDERLEY. (2003). Representação gráfica de ações em ilustração;

- Thiago LYRA. (2002). Ilustrações digitais em livros infantis: uma análise de técnica e estilo;

- Patrícia Bahia VANDERLEI. (2002). Análise gráfica das mensagens visuais nas escolas do Recife.

\section{Projetos de Iniciação Científica no âmbito do GP InfoDesign:}

- Érika Simona dos Santos FERREIRA. (2006). O estudo do processo de desenho de crianças entre 5 a 12 anos da Inglaterra, França e Brasil;

- Tiago Costa MAIA. (2005). Estudo da freqüência de uso dos componentes gráficos do desenho de memória pós-observação;

- Tâmara de Andrade BAIA. (2005). Estudo da seqüência de uso dos componentes gráficos do desenho de memória pós-observação;

- Érika Simona dos Santos FERREIRA. (2005). Estudo da ordem e hierarquia (freqüência + seqüência) de uso dos componentes gráficos do desenho de memória pós-observação.

- Eva Rolim MIRANDA. (2004). A freqüência de uso dos componentes gráficos durante o processo de desenho de observação: uma comparação entre Inglaterra e Brasil;

- Bárbara Gomes FORMIGA. (2004). A seqüência de uso dos componentes gráficos durante o processo de desenho de observação: uma comparação entre Inglaterra e Brasil;

- Eva Rolim MIRANDA. (2003). Estudo da freqüência de uso dos componentes gráficos durante o processo de desenho de memória;

- Bárbara Gomes FORMIGA. (2003). Estudo da seqüência de uso dos componentes gráficos durante o processo de desenho de memória;

- Cecília Vital Torres BARBOSA. (2002). Estudo da atitude das crianças durante o processo de desenho nos diversos contextos sócio-educacionais;

- Eva Rolim MIRANDA. (2002). O estudo das diferenças e similaridades na rotina global de desenho nas escolas.

\section{Dissertações concluídas na linha de pesquisa - Mestrado em Design, UFPE:}

- Leonardo Araújo da COSTA. (2006). O MECOTipo: revisão e desenvolvimento de um método de ensino de desenho coletivo de caracteres tipográficos;

- Eva Rolim MIRANDA. (2006). As crianças e os adultos como originadores de artefatos gráficos comunicacionais;

- Renata Garcia WANDERLEY. (2005). Uma abordagem para a representação gráfica de ações dinâmicas.

\section{Dissertações em andamento na linha de pesquisa - Mestrado em Design, UFPE:}

- Verônica Emília Campos FREIRE. A eficácia de imagens em livros didáticos infantis de língua portuguesa: parâmetros e recomendações para seu uso. Previsão: 2007;

- Maria Teresa LOPES. Design nas escolas fundamentais Brasileiras: muito prazer em conhecer! Previsão: 2008. 


\section{Infodesıgn}

\section{Tese em andamento na linha de pesquisa - Doutorado na Panthéon Sorbonne, Paris 1:}

- Eva Rolim MIRANDA. As crianças e os adultos como originadores de artefatos gráficos comunicacionais: uma investigação. Previsão: 2009.

\section{Pesquisas em andamento no âmbito do GP InfoDesign:}

- Sílvio Romero Botelho Barreto CAMPELLO. Artefatos Educacionais.

- Solange Galvão COUTINHO. O processo de desenho infantil em diferentes contextos sócio-educacionais;

- Solange Galvão COUTINHO \& Bernard DARRAS. O estudo do processo de Desenho de Memória (ordem curta) de crianças do Brasil e da França;

- Renata Garcia WANDERLEY. Imagens dinâmicas na educação: um estudo sobre a representação gráfica de ações em livros didáticos.

\section{Considerações finais}

Os nossos conceitos de arte, desde os tempos de colônia, sempre vieram de fora, como uma imposição através da produção artística européia. Hoje, mudando o contexto de colônia para país economicamente dependente, continuamos valorizando o que é de fora. O sistema educacional é um reflexo dessa dependência. Todos os modelos e parâmetros utilizados para o ensino da educação artística levam nas suas origens os modelos americanos, em sua maioria, implicando uma renúncia de consciência social, podendo ser somente Paulo Freire considerado um formulador de um modelo realmente brasileiro (Barbosa, 2001). Os parâmetros curriculares derivam deste panorama histórico, excluindo a análise da finalidade e aplicação da arte nas linguagens. Não é discutido o trabalho da arte e como ela é produzida. Ela é evidenciada como um 'dom natural', exaltando o mito em torno do processo de produção e criação.

Tornam-se urgentes, portanto, correções, de forma a legitimar a arte como campo específico na organização do conhecimento, porém, o capital cultural da nossa sociedade mantém a arte em papel reduzido. Isso acontece através do conceito de 'dom' e que a arte é produzida por 'gênios', negligenciando a função social da arte e do desenho. Aparentemente, as mudanças foram realizadas, e podemos considerá-las um passo para uma nova postura em relação ao desenho e à arte/educação nas escolas. Todavia, há preocupação de como serão introduzidos conceitos sobre a linguagem gráfica na escola, e sobre o objetivo de tais atividades, ou seja, de como analisar a produção infantil. Os parâmetros do MEC mencionam que as atividades artísticas serão ministradas por professores multidisciplinares até à $7^{\text {a }}$ série do Ensino Fundamental e, em seguida ministradas por Arte/Educadores. Desta forma as crianças passam dos 2 aos 13 anos desenhando sem nenhum objetivo real. Como esperar que depois de tantos anos sem instruções eficazes, os alunos tenham um desenho compatível com a sua capacidade intelectual?

Barbosa (1991, p:11) questiona o fato de que, nos cursos superiores, poucas são as disciplinas cujo foco de atenção esteja direcionado para a criatividade. Como os professores vão estimular o lado criativo dos alunos se os mesmos não têm acesso a tais informações? Além disso, Barbosa (Op.cit.) alerta para a importância do desenvolvimento de atividades envolvendo a imagem, tanto do ponto de vista das artes visuais como do ponto de vista do design e da publicidade.

Talvez por desinformação e conseqüentemente insegurança, os professores ainda caminham com precaução em relação ao uso de imagens na sala de aula. Sabemos que elas são elementos complexos e que o processo de decodificação não é simples. São necessários: observação, atenção e esforço em aprender e/ou ensinar o que se vê. Dondis (1997, p:228) afirma que "assim como se leva tempo para aprender a ler, a articular bem as palavras, leva-se tempo também na tentativa de alfabetizar-se visualmente".

No cinema, na TV, nos hospitais, na rua, enfim, hoje, em grande parte das situações, as imagens estão presentes como meio de comunicação e informação. Na escola, as imagens também podem e devem se apresentar como personagens principais de uma trama, auxiliando no processo de ensino e aprendizagem, porém como aponta Barbosa:

'As únicas imagens na sala de aula são as imagens ruins dos livros didáticos, as imagens das folhas de colorir e, no melhor dos casos, as imagens produzidas pelas próprias crianças. (...) Mesmo nas escolas particulares mais caras a imagem não é usada nas salas de aula de arte. Elas lecionam arte sem oferecer a possibilidade de ver. É como ensinar a ler sem livros na sala de aula (Barbosa, 1991, p:12, grifo nosso).'

Esta afirmação de Barbosa (1991), aliada a nossa experiência de pesquisa no ambiente educacional, nos faz refletir sobre o uso restrito e de qualidade questionável de imagens, e da linguagem gráfica na escola. Existe um desconhecimento por parte do professor de arte, ou de 
qualquer outra disciplina, acerca da importância da cultura visual e do uso da imagem como suporte didático. O professor ainda transita com cautela no ambiente da produção de imagens, e não é de se estranhar, visto que ele pouco, muito pouco, se familiariza com o universo imagético durante sua formação. O que pode ser feito para melhorar esta situação?

O papel do designer, enquanto profissional da área de comunicação e informação, deveria

ser convocado para a avaliação e a elaboração dos artefatos comunicacionais para educação. $O$ design possui as ferramentas necessárias para construir uma mensagem visual, de maneira que a torne compreensível, tanto do ponto de vista gráfico quanto informacional, de forma a evitar ambigüidade e otimizar o processo de compreensão de significado.

É preciso repensar a formulação do livro didático infantil de forma que não prejudique a eficiência do ensino e nem dificulte o aprendizado da criança. $O$ enfoque educacional deve equilibrar o desenvolvimento da percepção visual com as demais áreas do desenvolvimento infantil, e o livro, como ferramenta essencial para o pensamento, deve se configurar em seu aspecto textual, informativo e imagético, em um artefato cultural e intelectual de qualidade.

O designer hoje tem um novo papel na evolução do mundo. O processo de Design ganhou nova significação, ampliou seus horizontes e se depara com tarefas complexas tanto no que se refere a artefatos revolucionários quanto aos de tradição artesanal. O nosso grande desafio encontra-se na responsabilidade em gerar novos artefatos (incluindo aqui os de informação), com a consciência cultural e, conseqüentemente, com um compromisso com a sociedade.

\section{Referências}

BARBOSA, A. M. (2002). Inquietações e mudanças no ensino da arte. São Paulo: Cortez.

BARBOSA, A. M. (2001). John Dewey e o ensino da arte no Brasil. São Paulo: Cortez.

BARBOSA, A. M. (1991). A imagem no ensino da arte: anos oitenta e novos tempos. São Paulo: Perspectiva.

BUORO, A.B. (2002). Olhos que pintam. São Paulo: Cortez.

COUTINHO, S. G. \& FREIRE, V. E. C. (2006). Design para Educação: uma avaliação do uso da imagem nos livros infantis de Língua Portuguesa. Anais do $15^{\circ}$ Encontro Nacional da ANPAP - arte: limites e contaminações. Salvador: ANPAP. www.anpap.org.br.

COUTINHO, S. G. \& VANDERLEI, P. B. (2003). Análise gráfica das mensagens visuais nas escolas do Recife. Anais do 30 Encontro Internacional de Arte e Tecnologia e 120 Encontro Nacional da ANPAP - Associação Nacional de Pesquisadores em Artes Plásticas: a arte pesquisa. Julho de 2003. Brasília, DF: ANPAP/UNB. CR-ROM.

DONDIS, A. D. (1997). Sintaxe da linguagem visual. $2^{a}$.ed. São Paulo: Martins Fontes.

COELHO, L.A.L. (2005). Mudando de patamar: a pesquisa no design. InfoDesign - Revista Brasileira de Design da Informação, 2/1, pp. 36-40.

EDWARDS, B. (1984). Desenhando com o lado direito do cérebro. Rio de Janeiro: Ediouro.

FORMIGA, B. G. (2003). Nem tudo que tem tecla é computador - um estudo sobre o processo de desenho das professoras primárias do Recife. Monografia de graduação não publicada. Departamento de Design. Universidade Federal de Pernambuco.

FREIRE, Verônica E. C. (2005). A função semântica de imagens em livro didático infantil de Língua Portuguesa. Monografia de graduação não publicada. Departamento de Design. Universidade Federal de Pernambuco.

GOLSMITH, E. (1984). Research into illustration: an approach and a review. Cambridge: Cambridge University Press.

MEC - Ministério da Educação. (2005). Secretaria de Educação Fundamental. Departamento de Políticas Educacionais. Coordenação Geral de Educação Infantil. Guia Nacional do Livro Didático. Brasília: MEC/SEF/DPE/COEDI.

MOREIRA, A. A. A. (1999). O espaço do desenho: a educação do educador. $8^{a}$ ed. São Paulo: Loyola.

PORCHER, L. (1982). Educação artística: luxo ou necessidade? $5^{a}$ ed. São Paulo: Abril Cultural. 


\section{InfĐdesıgn}

\section{Sobre a autora}

Solange Galvão Coutinho é designer com interesse em design da informação e educação. Ph.D em Tipografia e Comunicação Gráfica pela Universidade de Reading, Inglaterra (1998). Desde 1986, é professora e pesquisadora do Departamento de Design da UFPE. Líder do Grupo de Pesquisa em Design da Informação criado em 2001. Atualmente é Diretora de Cultura da UFPE. Membro da Equipe do Centre de Recherche Images, Culure et Cognitions (CRICC) da Université Paris 1 - Panthéon Sorbonne.

solangecoutinho@globo.com 